\title{
FORMAS DE INFLUÊNCIA DAS ONGs NA POLÍTICA INTERNACIONAL CONTEMPORÂNEA
}

\author{
Rafael A. Duarte Villa \\ Universidade Federal do Paraná
}

\section{RESUMO}

Este artigo analisa a crescente importância que os atores não-estatais transnacionais vêm assumindo para a teoria das relações internacionais. Especificamente, o autor explora três aspectos: primeiro, a proposta da categoria de influência como meio político de atuação das ONGs transnacionais; segundo, a inserção destas em processos sociais globais — tais como desequilíbrios ecológicos, direitos humanos, consumo - e, finalmente, os métodos de criação de consenso em torno de problemas sociais de ordem planetária. Conclui-se que a atuação das ONGs atinge os planos interestatais, supranacionais e transnacionais.

PALAVRAS-CHAVE: ator transnacional; ONGs; influência; ator interestatal; ator supranacional; consenso; descentralização.

\section{INTRODUÇÃO}

No pensamento realista (cf. ARON, 1986 e MORGENTHAU, 1986), as relações internacionais são definidas como "relações interestatais", o que indica que, nessa concepção, o ator fundamental no plano internacional é o Estado-nação, e os atores não-estatais são relegados à condição de "ambiente" da política interestatal. Na base dessa última assunção está a idéia de que, no confronto dos atores transnacionais não-estatais com o Estado-nação, as razões deste último tendem a prevalecer. Essa hipótese não é errada. Os Estados, em confronto com outros atores do sistema internacional, prevalecem em função do maior poder relativo de que dispõem e também da maior legitimidade em face das sociedades que representam. No entanto, os meios pelos quais o Estado nacional prevalece, o da coação e da legitimidade, nem sempre são eficientes, dado que os custos gerados pela prevalecência do seu caráter soberano podem ultrapassar os ganhos. Neste século, por exemplo, países do Terceiro Mundo (como o México de Cárdenas, em 1940; o Irã de Mossadegh, em 1951; e a Venezuela do primeiro governo de Carlos Andrés Pérez, em 1976) puderam nacionalizar as suas indústrias petrolíferas e até expulsar as multinacionais do ramo, mas os custos posteriores em investimento de capital, contratos de serviços e pacotes tecnológicos trouxeram-lhes onerosos débitos. Esses efeitos perversos abrem, assim, mais es- paço para a barganha entre o ator estatal e o transnacional.

Como constata Gilpin (1989), novos tipos de atores transnacionais, mais sensíveis à moderna ciência, à tecnologia e às mudanças econômicas e ecológicas, têm quebrado o monopólio do Estado na administração e governo do sistema internacional, respondendo às profundas mudanças nos padrões da tecnologia — sobretudo nas comunicações e no transporte - que fizeram com que as sociedades nacionais se voltassem para a problemática contida nos temas que afetam o bem-estar econômico, a saúde física e psíquica dos indivíduos de outras sociedades além das fronteiras. A revolução nas telecomunicações (TV, satélites, microinformática), bem como a acelerada modernização dos transportes (aviões, navios e automotores), tornaram possível que cidadãos e políticos "vissem" a agregação de microações em macroresultados. As sociedades puderam então observar, ao vivo, pronunciamentos oficiais, a resposta dos adversários, os comentários dos manifestantes, a fuga dos refugiados e outras variedades de acontecimentos que conduzem ao consenso, apoio ou rejeição das posturas abordadas (cf. ROSENAU, 1992). Enfim, a celeridade das mudanças nas comunicações e nos transportes tende a se acentuar, trazendo a idéia da "aldeia global" para um nível mais concreto. Pense-se na revolução que as chamadas "autoestradas eletrônicas" ou redes internet estão sus- 
citando na década de noventa.

Tomassini (1984) elenca um conjunto de características que renovam e redefinem o papel dos atores não-estatais nas relações internacionais contemporâneas. De acordo com esse autor, as relações internacionais contemporâneas apresentam, em primeiro lugar, grande diversificação de centros de poder, cuja atuação deixa de ser pensada em função do Estado para incorporar a sociedade civil organizada. Em segundo, surge uma agenda de discussões internacionais ampliada e menos hierarquizada, isto é, a sua definição é menos centralizada. Finalmente, as novas problemáticas são geridas por múltiplos agentes distintos do Estado. Em decorrência disso, colocam-se em cena formas de poder não-tradicionais, em uma arena mais abrangente e diferenciada. Em outras palavras, parecem consolidar-se formas de interdependência de processos interestatais, transnacionais e supranacionais, já descritos por Aron (1997, p. 25-28) no conceito de sociedade internacional ou mundial. Aron nos Os últimos anos do século descreve o conceito de sociedade internacional ou mundial, como "uma totalidade que incluiria ao mesmo tempo o sistema interestatal, o sistema econômico e os movimentos transnacionais, as sociedades e as instituições supranacionais" (ARON, 1997, p. 27).

Neste ponto, interessa descrever o tipo de ator transnacional que se articula nos processos sociais globais e que interage com os outros planos da sociedade mundial. De acordo com diferentes autores, o agente transnacional tem sido definido como "forças" (HOFFMAN, 1970), "unidades sociais" (MENDERSHAUSEN, 1969), "atores sociais" (KAISER, 1971) ou "microator" (ROSENAU, 1992). Uma definição abrangente de ator transnacional poderia ser a que segue: agente societal que estabelece um tipo inovador de vinculações extra-estatais, baseando-se em contatos, coligações e interações através das fronteiras nacionais ante os quais os órgãos centrais da política externa estatal ou supranacional têm relativa, ou nenhuma, capacidade regulatória. Com relação aos tipos concretos de atores, parece existir, contemporaneamente, um consenso de que os dois tipos principais são as empresas multinacionais (EMNs) e as organizações nãogovernamentais (ONGs). Por razões de espaço, neste artigo, a análise se dirige às segundas.

\section{ATORES TRANSNACIONAIS NÃO-GO- VERNAMENTAIS OU ONGs}

As organizações não-governamentais (grupos ecológicos, pacifistas e de direitos humanos, entre outros) são atores menos hierarquizados e mais descentralizados que as multinacionais. As ONGs destacam-se por seu papel de representação ou expressão de grupos sociais nacionais ou internacionais, abordando um variado espectro de atividades, como a política, a economia, a religião, a cultura, a cidadania e a ecologia. A profundidade de sua ação é desigual à medida que podem passar do plano da pressão ao do confronto político ou à ação direta. São exemplos desses tipos de atores a Fundação Ford, o grupo ecológico Greenpeace, a Anistia Internacional, a União Internacional de Mulheres, entre outros.

A institucionalização e crescimento das ONGs é viabilizada por fatores diversos: a apresentação da problemática com intensidade tal que mais pessoas e recursos sejam necessários para regular o processo; a necessidade de cooperação e coordenação em medidas e programas sociais em regiões do Terceiro Mundo; a facilidade de operacionalizar as ações em situações de emergência, como, por exemplo, na guerra civil da Ruanda, de 1994, em que milhares de refugiados receberam com mais rapidez a assistência das ONGs humanitárias que a ajuda alimentar dos fuzileiros americanos; e, finalmente, a intensidade de processos transnacionais como os desequilíbrios ecológicos, que estimulam o crescimento de grupos transnacionais, como vem acontecendo com o Greenpeace, que hoje possui perto de seis milhões de associados.

As ONGs, enquanto atores transnacionais, tiveram a sua mais rápida expansão no período do segundo pós-Guerra. Em 1914 existiam trezentos e trinta, em 1939 seu número subiu para setecentos e trinta e, em 1980, alcançavam um impressionante total de seis mil (cf. JACOBSON, 1989, p. 31). Esse crescimento acelerado do número de atores transnacionais baseou-se em várias precondições, entre as quais a modernização tecnológica destaca-se como primeira causa. O desenvolvimento dos meios de comunicação e transporte permitiu desenvolver a capacidade organizacional para operar através de imensas distâncias e multiplicidade de culturas. Outra importante condição, de caráter político, foi o pluralismo ocidental, que criou condições para uma maior organização societal. Essas duas 
precondições não se apresentaram, entretanto, como isoladas, mas como interdependentes, de forma que se deu uma relação quase direta entre crescimento das ONGs, modernização e pluralismo político. Essa relação é sugerida pelos seguintes dados: em meados da década de sessenta, aproximadamente cinquienta por cento das ONGs localizavam-se na América do Norte e na Europa ocidental, enquanto que $16 \%$ estavam na América Latina, seis por cento na África negra, oito por cento na Ásia pró-ocidente, sete vírgula cinco por cento no leste europeu e meio por cento na Ásia socialista (cf. SKJELSBAEK, 1983, p. $81)$.

Sintetizando, as ONGs transnacionais societais tiveram sua expansão facilitada pela rápida modernização ocidental e pelo pluralismo político. Se se considera, então, a prática concreta das relações transnacionais e as interações destas com os planos interestatais e supranacionais, torna-se relevante a seguinte questão: qual é o mecanismo político específico que permite aos atores transnacionais não-governamentais societais inserirem-se nos processos de decisão? De certa maneira, essa pergunta renova e redefine a noção de influência, da qual passaremos a tratar em seguida.

\section{A NOÇÃO DE INFLUÊNCIA}

Uma característica fundamental dos novos processos incorporados na agenda internacional é o seu "caráter descentralizado", querendo-se expressar com este termo o fato de que, agora, a busca de soluções políticas e técnicas escapa ao monopólio estatal. O fato de os fenômenos de crescimento populacional, migrações internacionais e desequilíbrios ambientais serem descentralizados abre uma extensa possibilidade de os atores transnacionais societais virem a influenciar os centros de decisão estatal e supranacional relacionados com a implementação de políticas globais. Dessa forma, a categoria de influência proporciona o instrumental teórico que permite localizar os limites reais da ação política do ator transnacional no sistema internacional do pósGuerra Fria.

O conceito de influência em geral sofre de grande imprecisão teórica. Apesar dessa falha ser facilmente constatada, o conceito vem sendo pouco trabalhado no seu significado, sendo utilizado, na maioria dos casos, como sinônimo de poder. Nessa direção, Dahl define a influência como "uma relação entre agentes em que um induz outros a agirem de uma forma que de outra maneira não agiriam" (DAHL, 1966, p. 72 e p. 90). Assim definida, no entanto, a influência não se diferencia do conceito de poder enquanto relação social na qual a vontade manifesta de um ator impõe seu desejo sobre outras vontades; por isso, a definição de influência de Dahl apresenta certamente uma contradição. Poder e influência não são conceitos equivalentes, e essa confusão decorre de que não são identificados os meios do poder e os meios da influência. O meio específico do poder, no que coincidem autores como Weber, Marx e Gramsci, é a força, "a última ratio quando os outros meios fracassam" (WEBER, 1944, p. 44). É esta especificidade o que diferencia o Estado das demais comunidades políticas, na medida que o Estado controla o monopólio legítimo da força e, portanto, controla a possibilidade de coação e de coerção.

É necessário, então, definir o conceito de influência e determinar qual é o seu meio específico. Os atores estatais no plano internacional servem-se de meios violentos (coerção) e não-violentos (consenso) para ter sucesso nos desejos exprimidos por suas vontades; em outras palavras, servem-se de "boas armas e boas leis". Dessa forma, a existência da coação, condição necessária embora não suficiente do poder político, representa a diferença entre poder e influência: um ator tem poder de mando, em última instância, na medida em que controla a coerção física; quando carece desta, mas se vale de meios consensuais para conseguir o objetivo de encontrar obediência nas vontades alheias, tem influência. Parodiando Maquiavel, poder-se-ia expressar que só resta aos modernos profetas sem armas, ao estilo das ONGs, fundamentalmente, o expediente da influência. Assim, a especificidade da influência é equivalente ao que Weber chamou de ação politicamente orientada: "Diz-se que uma ação é politicamente orientada quando e na medida em que tende a influir na direção de uma associação política, particularmente na apropriação ou expropriação, na nova distribuição ou atribuição dos poderes governamentais [...]. É certo que a linguagem corrente chama 'associações políticas' não apenas àquelas, sustentáculos da coação considerada como legítima, como também a partidos e clubes com pretensão de influir (sem violência, segundo declarações próprias) na ação política da associação. Deve-se, entretanto, se- 
parar este tipo de ação social, politicamente orientada, da autêntica ação política da associação" (WEBER, 1944, p. 44-45, sem grifo no original).

Em outros termos, as situações de influência encontram sua especificidade quando a ação política é instaurada no nível daquilo que Gramsci chamaria de hegemonia, isto é, quando a política é exercida não com o recurso da ultima ratio, mas sim por via do consenso, que se manifesta como direção política e cultural de um grupo que vê realizadas determinadas concepções culturaisideológicas do mundo. Entretanto, não se pode deduzir daí que a força, como instância última da manutenção da dominação, desapareça: mantémse em potencialidade para reaparecer quando a preservação da ordem estabelecida o exigir. A diferença é que, nesse momento, a política retoma sua especificidade de poder político, que o meio da força lhe confere.

Até este momento, limitamo-nos à descrição da influência do ponto de vista da ordem interna. Entretanto, as relações transnacionais, como já dito, desenvolvem-se em um locus diferente: a sociedade internacional, nos seus planos interestatal, supranacional e transnacional, e, nesse patamar de análise, as relações de influência tendem a atingir um nível menos regulado e pautado que o esperado nas relações entre atores na ordem interna - ainda que se conservem os pontos teóricos sobre influência e poder descritos acima. Dessa forma, a categoria influência torna-se a chave que permite medir e explicar em termos mais concretos (e sobretudo menos apocalípticos para o Estado nacional) o alcance efetivo da ação transnacional. No nível da transnacionalização, a influência se torna, desse modo, a capacidade de determinar certos resultados independentemente das estruturas formais de autoridade (cf. TOMASSINI, 1984). Os atores transnacionais não estariam interessados em estabelecer formas diferenciadas de poder político ou em concorrer por ele (instrumentalizado na fórmula clássica marxista-weberiana de controle do aparato estatal), mas se interessariam por orientar sua ação política de tal forma a gerar consenso em torno do conteúdo de sua atuação, resultante de suas inserções nos processos globaistransnacionais.

Neste ponto, iremos nos deter brevemente na definição de Tomassini. A cláusula "independentemente das estruturas formais de autoridade" não tem uma consequiência prática, e sim teórica: ela não quer significar que os atores não-governamentais transnacionais agem como se não tivessem como interlocutor o Estado enquanto forma de autoridade. Logicamente, as interações transnacionais pressupõem isso. Também não se quer expressar que os atores transnacionais se comportem anarquicamente, bem no estilo estatocêntrico. Com essa cláusula procura-se sublinhar a idéia de que os atores transnacionais não precisam reproduzir formas domésticas de autoridade (no sentido das tipologias weberianas) para poder articular-se nos processos de decisão, implementação e monitoramento de políticas de prevenção ou controle dos novos fenômenos de segurança. Seu caráter de "expressão e representação societal" não tem como fundamento a tradição, o carisma ou os mecanismos legais-racionais do Estado moderno. A fonte da "autoridade" dos atores transnacionais tem que ser procurada antes no caráter quase dramático do debate no qual se articulam: isto é, nas respostas societais globais que apresentam, em face dos desequilíbrios sistêmicos gerados pelos novos fenômenos transnacionais de segurança tais como os desajustes globais ecológicos e a forma como aqueles desequilíbrios afetam os aspectos de bemestar da economia, da saúde, da identidade cultural e da qualidade de vida dos cidadãos em todo o planeta. São estes os fenômenos para os quais o Estado nacional não têm resposta imediata; por outro lado, fenômenos como esses permitem preencher com legitimidade a ação dos grupos transnacionais. Adicionalmente, tais problemáticas estão muito próximas e são muito sensíveis ao cotidiano dos indivíduos, e essa peculiaridade permite aos atores transnacionais não-governamentais tornarem-se consciências críticas societais globais e interdependentes, inclusive passando a exercer funções que, em tese, deveriam ser assumidas pelos representantes eleitos através dos mecanismos democráticos nacionais, como foi notável na ECO-92: “os grandes ausentes da Conferência do Rio foram precisamente os parlamentares [...]. Os organizadores da conferência se preocuparam em garantir a presença das ONGs, mas se esqueceram de um 'pequeno' detalhe: convidar os legítimos representantes da sociedade civil" (GUIMARÃES, 1992, p. 98).

Em resumo, a influência é o meio específico que permite aos atores transnacionais desenvolver uma ação política dirigida - como definida por Weber. Com base nisso, resta definir como se exprime o exercício concreto dessa influência 
nos processos transnacionais.

\section{A INSERÇÃO DAS ONGs NOS PROCES- SOS TRANSNACIONAIS}

Além de maneiras concretas de influência, a inserção dos atores não-governamentais nos processos transnacionais define as formas por que os atores exprimem maneiras concretas de interdependência entre os atores supranacionais e os outros planos da sociedade internacional. Essas formas de influência e interdependência compreendem parâmetros quantitativos e qualitativos.

Quantitativamente, o melhor exemplo seria a ampla participação de delegados das ONGs nas "conferências sociais globais", nas quais manifestam sua presença através de fóruns paralelos, como adidos das delegações oficiais ou como observadores nos eventos oficiais. Foram vinte mil delegados na Conferência sobre Meio Ambiente e Desenvolvimento, ou Rio-92 (cf. GUIMARÃES, 1992, p. 87); duas mil ONGs representadas na "Conferência de Viena sobre Direitos Humanos" (cf. ALVES, 1994, p. 170); dois mil delegados na "Conferência sobre População e Desenvolvimento", ou Cairo-94 (cf. ALVES, 1995, p. 13); dez mil delegados na "IV Conferência sobre Direitos da Mulher", ou Pequim-95 (cf. VALENTE, 1996, p. 48), e perto de dois mil e quinhentos na "Conferência sobre Assentamentos Humanos" de Istambul-96, ou Habitat-II ( $O$ Estado de S. Paulo, 1996, C-4).

Outra forma de visualizar o alcance quantitativo da influência desses atores é proporcionada pelas quantias que administram: em 1992 os orçamentos de duas das principais organizações ambientalistas transnacionais, o Greenpeace International e a World Wildlife Fund foram, respectivamente, de cem e duzentos milhões de dólares. O orçamento do Programa Ambiental das Nações Unidas (PNUMA) só chegou no mesmo ano aos setenta e cinco milhões. Também o número de associados é eloqüente: juntas, as ONGs mencionadas tinham, em 1994, aproximadamente seis milhões de membros (cf. WAPNER, 1995, p. 315).

$\mathrm{O}$ aspecto qualitativo refere-se à faceta propriamente política da ação do ator transnacional. Concretamente, o processo em questão varia de acordo com o que está em jogo e de acordo com o ator - estatal, supranacional ou mesmo transnacional - que lhe serve de interlocutor.
Passaremos agora a analisar alguns planos em detalhe, cumprindo a seguinte ordem: em primeiro lugar, analisar-se-á o sistema interestatal; em seguida, o supranacional, para chegar-se, finalmente, ao sistema transnacional.

\section{IV.1 O sistema interestatal}

As pressões dos grupos transnacionais societais, no plano interestatal, podem ser dirigidas a um Estado só. Foi o que aconteceu em 1989, no Brasil, com o encerramento dos trabalhos da usina nuclear Angra I, considerada até hoje a maior vitória do movimento ecológico brasileiro. Também nesse plano estão as ações dos movimentos de defesa das minorias e dos imigrantes nos Estados Unidos - como a Anistia Internacional e pelo menos vinte ONGs (cf. Jornal do Brasil, 02/04/1997, p. 12) — que pressionam a nova lei de imigração, de abril de 1997. Este dispositivo legal, entre outros procedimentos, viabiliza a deportação de estrangeiros e impede que os deportados regressem legalmente aos EUA; adicionalmente, bloquea o uso dos serviços sociais, como saúde, educação, maternidade de mais de cinco milhões de imigrantes em situação irregular no país e de mais de um milhão de imigrantes em situação legal mas que estão no país há menos de dez anos (cf. Jornal do Brasil, 06/04/1997, p. 22).

Nos dois casos referidos acima, as ações do ator estatal e do transnacional não têm como único pano de fundo o problema ecológico e o migratório. Como revela o debate sobre a nova lei de imigração americana, existem outras clivagens internas que determinam o posicionamento dos atores. O governo de Clinton atenta para as demandas de setores republicanos, que desde a campanha eleitoral presidencial de noventa e seis fizeram dos controles sobre os migrantes um ponto programático; dessa forma, o escopo institucional da ação das ONGs que defendem as minorias étnicas e migrantes não passa somente pelo governo mas atinge também outras estruturas do Estado, como os partidos, o Congresso e o Judiciário. Exatamente para este último nível, o Judiciário, dirigir-se-á no futuro a ação das ONGs para tentar mudar ou diminuir o impacto da nova lei (cf. Jornal do Brasil, 06/04/1997, p. 22).

Num plano levemente diferenciado, as pressões podem ser dirigidas a um subsistema intergovernamental como a ONU, o Banco Mundial, o Tratado Antártico, entre outros. Foi o caso 
da Antártida, onde os atores ecológicos, representados pelo Greenpeace, agiram com muita eficácia - através da presença direta, mobilização da opinião pública e pesquisas — para influenciar o Protocolo de Madri, instrumento legal dos países do Tratado Antártico que congelou por cinqüenta anos qualquer possibilidade de prospecção mineral na Antártida. Aliás, é interessante registrar que o Greenpeace é o único ator não-estatal que tem uma base de operações científicas na Antártida e o único que participa com status de parte não-consultiva - isto é, com direito a voz mas sem voto - das reuniões do Tratado Antártico ${ }^{1}$. Outro exemplo interessante, que envolve uma influência simultânea sobre um Estado e um subsistema interestatal - no mesmo âmbito ecológico-, deu-se no Brasil através da aliança entre organizações ambientalistas brasileiras e americanas (particularmente a Environmental Defense Fund, National Wildlife Federation e Sierra $C l u b$ ) em torno do projeto de construção da estrada Porto Velho-Cuiabá. Em 1981, o Banco Mundial aprovou o financiamento do asfaltamento da BR-364, que liga Cuiabá a Porto Velho. Como havia sido previsto por algumas entidades ambientalistas, o projeto originou um impacto desolador sobre bosques e populações indígenas. Em 1984, o governo brasileiro apresentou um projeto de financiamento ao Banco Interamericano de Desenvolvimento (BID) para a construção do tramo Porto Velho-Rio Branco. A possibilidade de que os mesmos resultados originados da construção da BR-364 viessem a se repetir originou uma forte reação das entidades ambientalistas brasileiras e americanas e aquelas de defesa dos povos indígenas (cf. VIOLA, 1992, p. 148). A partir daí, as pressões foram dirigidas tanto ao governo brasileiras quanto ao BID: "Embora o governo brasileiro aceitasse em 1985 as condições do BID, a implementação do projeto estava longe daquilo que tinha sido acertado, resultando na resistência organizada da coalizão ambientalista. Em inícios de 1987, os representantes dos seringueiros, dos indígenas, dos ambientalistas brasileiros e antropólogos brasilei-

1 Este tratado foi assinado, inicialmente, em 1959 e reunia todos os países que têm instalado uma base científica ou que fazem reivindicações de soberania: Chile, Argentina, Inglaterra, Estados Unidos, Japão, Noruega, Austrália, Nova Zelândia, África do Sul, China, União Soviética, França e Espanha. O Brasil só se integrou ao Tratado em 1983. ros realizaram uma pressão sistemática sobre todos os organismos brasileiros comprometidos com o projeto; similar estratégia de pressão foi desenvolvida na assembléia anual do BID [...]. Como resultante desta pressão o BID suspendeu os desembolsos financeiros em dezembro de 1987 [...]" (Jornal do Brasil, 06/04/1997, p. 22).

Finalmente, as conferências sociais globais têm constituído um excelente palco do exercício da influência dos atores transnacionais societais, apontando com precisão para a interdependência de atores estatais e transnacionais. Nesse sentido, a influência aparece também sob a forma de capacidade de proposta, maneira de atuação esta que se consolidou desde o início das conferências globais sociais. Fracassos e sucessos caracterizam, entretanto, essa maneira particular de influência. No lado dos insucessos, podem ser alinhados alguns exemplos: na Eco-92, a proposta das ONGs ambientalistas - feita junto com algumas organizações intergovernamentais como o BID e a CEPAL - de que os países do Norte deviam pagar uma "dívida ecológica" aos países do sul, por serem os primeiros responsáveis por um padrão de desenvolvimento e de tecnologia gerador de boa parte dos desequilíbrios ecológicos e da pobreza dos segundos (cf. GUIMARÃES, 1995, p. 117). Na Cairo-94, pode ser considerada, em parte, mal-sucedida a proposta dos países do sul, apoiada pelas ONGs, de criar um "direito internacional de reunificação familiar dos migrantes" (em parte porque, apesar da recusa dos países do Norte em assinar tal proposta, o capítulo dez do plano de ação ("das migrações internacionais") ${ }^{2}$ da conferência do Cairo acolheu a fórmula consensual de que "todos os governos devem reconhecer a importância vital da reunificação familiar e promover sua integração na legislação nacional [...]" (NAÇÕES UNIDAS, 1994). Em compensação, a conferência de Viena sobre os direitos humanos representou, em matéria de aprovação de propostas, sonoras vitórias das ONGs societais. Concretamente, foi aprovada pela conferência a polêmica proposta da Anistia Internacional de criação de um AltoComissariado para os Direitos Humanos no âmbito das Nações Unidas. Idéia amplamente discu-

\footnotetext{
2 A partir da Conferência de Viena sobre os direitos humanos, a discussão dos diferentes temas de cada conferência se condensa no que se chama "plano de ação", a cada tema corresponde um capítulo.
} 
tida em setenta e oitenta, a sugestão da conferência (cf. ALVES, 1994, p. 176) foi aprovada durante a XLVIII Sessão da Assembléia Geral das Nações Unidas em dezembro de 1993. De forma genérica, esse organismo terá a função de promover e proteger todos os direitos humanos. As barreiras levantadas por aqueles grupos de países, principalmente os asiáticos, que detectavam na aprovação do Comissariado a possibilidade de ingerência indevida em sua soberania pelos países desenvolvidos, foram, dessa forma, transpostas (cf. ALVES, 1994, p. 177). E, particularmente, foi superado o argumento do "relativismo cultural", levantado por esses mesmos países, sobretudo pelos de maioria religiosa muçulmana.

Assim a inter-relação e o exercício da influência dos atores transnacionais societais, em relação ao sistema interestatal, exprime um dado real no qual intervêm diferentes inputs, como pesquisas, propostas, alianças e negociações, além de um impressionante aparato de propaganda, sobre o qual voltaremos a discutir mais à frente.

\section{IV.2 O sistema supranacional}

O exercício qualitativo da influência dos atores no sistema supranacional é talvez o menos considerado. Mas essa deficiência não decorre do fato de as ONGs subestimarem ou não terem estratégias para esse sistema: é antes uma conseqüência de que o plano supranacional é o menos consolidado das relações internacionais. Nesse sentido, não se pode confundir tendências para a formação de blocos econômicos com experiências supranacionais. Além de algumas instituições como a Corte Interamericana dos Direitos Humanos, só se pode falar numa única experiência supranacional strictu sensu: a União Européia, na qual as decisões de seus órgãos são obrigatórias devido a uma delegação anterior de competência dos Estados à Comissão ou ao Conselho, que compõem a UE.

A despeito das considerações acima, podem ser destacados alguns exemplos de interdependência na ação das ONGs com o sistema supranacional. Um desses casos é a proposta do Instituto Sindical Europeu de introduzir no Tratado de Maastricht (da União Européia) estatutos sociais e trabalhistas, com vigência supranacional, que enfrentem de alguma maneira as consequiências politicamente negativas como a xenofobia contra o trabalhador imigrante
- da globalização da economia mundial. Acredita aquele instituto que "criar padrões sociais e trabalhistas mínimos entre os diferentes blocos econômicos é uma exigência inadiável nos dias de hoje" (Jornal do Brasil, 06/04/1997, p. 20). Outro exemplo considerável, revelador da interseção de atores supranacionais, transnacionais e estatais, deu-se na conferência do Cairo. Na Declaração de Viena sobre os Direitos Humanos, redigida na conferência de mesmo nome, havia sido recomendado o reconhecimento do direito ao desenvolvimento como um "direito universal, inalienável, e parte integrante dos direitos humanos fundamentais". Essa recomendação foi adotada pela Assembléia Geral da ONU em dezembro de 1993 por oitenta e seis votos a favor, um contra (EUA) e oito abstenções (Dinamarca, Finlândia, Alemanha, Islândia, Israel, Japão, Suécia e Reino Unido) (cf. ALVES, 1994, p. 174). A expressiva abstenção de países da União Européia já fazia prever algum tipo de controvérsia no futuro; ela efetivamente aconteceu na Conferência do Cairo: a União Européia propôs no plenário que o princípio do "direito ao desenvolvimento" (acolhido a exemplo da Conferência de Viena) fosse retirado do documento final a ser aprovado. Com isto, o consenso que já havia sido conseguido em Viena ficaria fragilizado. Porém, a ação conjunta de ONGs e algumas delegações, como a brasileira, obrigou a UE a retirar a proposta (cf. MELLO VIANNA, 1995, p. 176).

\section{IV.3 O sistema transnacional}

No último plano de influência dos atores, as pressões podem envolver a disputa de atores transnacionais entre si. Estas disputas podem ser de atores societais versus multinacionais ou entre os próprios atores societais.

No primeiro dos casos, as multinacionais têmse constituído num dos alvos principais das críticas e das reações das ONGs transnacionais, devido, entre outros fatores, à memória trágica de alguns fatos envolvendo as multinacionais. Entre esses acontecimentos, há de se lembrar o desastre ecológico produzido em Alasca por um petroleiro da Exxon Valdez, em 1989, ou os três mil mortos e mais de duzentos mil feridos em Bophal (Índia), pelo vazamento do gás letal isocianato das indústrias da Union Carbide, em 1986 (cf. RADAKRISHNA, 1991, p. 100).

Alguns casos mais recentes ilustram de ma- 
neira muito clara a forma como as ações dos ativistas ecológicos conseguiram mudar as políticas de produção e de mercado de algumas multinacionais. Em 1990, a multinacional Uniroyal Chemical Company deixou de produzir o agente químico alar, usado na conservação de maçãs, depois que grupos de ativistas como Ralp Neder's Public Interest Research Group (PIRG) e Natural Resources Defense Council (NRDC) organizaram uma campanha pública maciça nos Estados Unidos e no mundo todo (cf. WAPNER, 1995, p. 326-338). Em 1984, a NRDC produziu um estudo segundo o qual o alar criava riscos de câncer duzentos e quarenta vezes mais altos do que supunha a Agência de Proteção Ambiental dos Estados Unidos (EPA). O estudo em questão foi apresentado no programa "60 minutos" da rede de televisão CBS. Ainda mais: os ativistas pressionaram os supermercados a parar de vender maçãs contendo alar. O efeito foi devastador: a demanda de maçãs caiu significativamente e seus preços chegaram a níveis muito baixos, resultando em perdas de cento e trinta e cinco milhões de dólares só no Estado de Washington. Esses efeitos e as pressões dos ativistas levaram a Uniroyal Chemical Company a parar de produzir a substância no mundo todo.

O caso da Uniroyal Chemical Company não constitui, entretanto, um caso isolado. Em 1991, a multinacional McDonald's Corporation decidiu parar de produzir sua tradicional caixa para hambúrguer, visando não usar mais materiais como espuma e plástico. Esses dois materiais têm na sua composição química o gás CFC responsável pelo buraco na camada de ozônio. A decisão da McDonald's foi o resultado da pressão de grupos ambientalistas como Earth Action Network e Kids against Polution, que organizaram um "abaixoassinado" no qual as pessoas sugeriam à McDonald's usar sacolas para servir o hambúrguer. Na esteira dessa campanha, os ativistas ecológicos aproveitaram para protestar pelas políticas ambientalistas da multinacional no mundo, de tal forma que ela viu-se forçada a estudar formas de reduzir os detritos sólidos produzidos por seus onze mil restaurantes espalhados pelo mundo (cf. WAPNER, 1995, p. 326). É claro que os “diretores da McDonald's não acreditam que faça muito sentido, ecológico ou econômico, parar de usar as caixas construídas à base de espuma e plástico [ou controlar os dejetos sólidos]. Mas eles estão respondendo a pressões dos ativistas"
(WAPNER, 1995, p. 327).

As formas de interdependência podem se manifestar entre atores transnacionais societais entre si. O debate em torno da relação entre população, meio ambiente e direitos reprodutivos exemplifica bem essas interações. De um lado, localizam-se aquelas organizações - principalmente as ONGs ambientalistas americanas de porte conservador - que sustentam um argumento neomalthusiano segundo o qual "existe uma relação direta e quase mecânica entre o crescimento populacional e o aumento da pobreza, escassez de alimentos e crise ambiental global", sem levar em conta " $[\ldots]$ os níveis extremamente diferenciados de padrões de produção, e de controle e acesso aos recursos entre as diferentes classes sociais [...]". A partir de diagnósticos desse tipo, "a formação de alianças entre importantes setores do ambientalismo norte-americano e as entidades de planejamento familiar fortaleceu imensamente o poder de mobilização das teses neomalthusianas junto à opinião pública e às agências provedoras de recursos para o controle populacional" (MELLO VIANNA, 1995, p. 172). De outro lado, encontra-se um setor do movimento internacional de mulheres (representadas pelas chamadas redes regionais e globais de mulheres como a Rede Feminista Latino-americana, a Rede de Mulheres Jovens, a Católicas pelo Direito a Decidir, entre outras) que opõe ao controle populacional os "direitos reprodutivos", isto é, o direito que mulheres e homens têm de escolher quando e com quem desejam ter filhos. Esse direito tem por fundamento o princípio de que as escolhas nas esferas reprodutivas não se realizam num vazio, mas baseadas em contextos econômicos, sociais, culturais, religiosos. Nas regiões rurais, mais filhos significam mais braços para a lavoura, por exemplo; ou, ainda, em sociedades de extrema pobreza os filhos significam a garantia de segurança na velhice dos pais. Os "direitos reprodutivos" também supõem que devem ser asseguradas todas as informações, métodos e serviços de saúde em condições adequadas e seguras tanto a quem deseja ter filhos como a quem não deseja (cf. MELLO VIANNA, 1995, p. 174).

Concluindo, o exercício da influência e as pressões das ONGs transnacionais não se limitam só a mudar as políticas oficiais dos sistemas estatais e supranacionais ou as políticas de lucro das multinacionais. É necessário reconhecer nelas um poder de iniciativa que ultrapassa a interação com 
esses planos. Talvez o exemplo mais nítido dessa autonomia seja a capacidade das ONGs de coordenar e desenvolver projetos de desenvolvimento sustentável em comunidades do Terceiro Mundo: parte-se do princípio de que essas comunidades podem ser educadas para proteger seu meio ambiente, apontando para efeitos sociais e locais positivos que também resultam em benefícios para o ambiente global (cf. SHIVA, 1991). Exemplo claro disso constitui a ONG World Wildlife Fund, que, nas últimas décadas, tem financiado projetos de conservação, reflorestamento ambiental e assistência técnica sanitária em vários países, entre os quais se destacam a Zâmbia, Camarões e Santa Lucia (cf. WAPNER, 1995, p. 331-332). Essas ações significam, obviamente, transferência de dinheiro para os países do Terceiro Mundo através das ONGs e suas representações. Assim, para 1989, as ONGs dos países do Norte direcionaram seis vírgula quatro bilhões de dólares aos países em desenvolvimento, o que representou doze por cento de toda a ajuda pública e privada dos países desenvolvidos (cf. LIVERNASH, 1992, p. 15).

Em resumo, os exemplos acima mostram que a ação das ONGs se espraia para além da influência quantitativa e qualitativa sobre os entes públicos e privados para inserir-se, também, no escopo estritamente societal. Isso tem levado alguns autores a sugerir que as ONGs estão em vias de construção e de institucionalização de um espaço público transnacional (cf. LEIS, 1996, p. 44-54). De certa forma, esse é um problema que tem a ver com a criação de novas formas de consenso e com a própria natureza societal e descentralizada dos novos processos de segurança, aspectos que abordaremos a seguir.

\section{A CONSTRUÇÃO DO CONSENSO}

A inserção das ONGs nos processos de influência não se afirma só nos aspectos quantitativos e qualitativos. Elas constituem atores que têm uma ação pragmática, ou seja, na criação do consenso transnacional elas definem estratégias específicas para atingir seus objetivos, descartando-se a possibilidade de ações caóticas. Afirmou-se, nas páginas anteriores, que um ator tem influência quando carece de meios de coerção, mas se vale de meios consensuais para conseguir o objetivo de encontrar obediência nas vontades alheias: justamente esse aspecto do ator transnacional é dos menos estudados na sua inserção nos processos transnacionais. A seguir se descrevem as estratégias que articulam formas de construir o consenso transnacional para em seqüência abordarse a descentralização dos processos transnacionais.

Numa primeira fase, os atores transnacionais têm como âmbito de atuação a sociedade nacional, onde se destacam, geralmente, no papel de consciência crítica de um problema de natureza societal. Ou, como prefere Hertz (1988, p. 77), o exercício de sua influência se dá, num primeiro momento, através de um locus cultural e social no interior das fronteiras nacionais. À medida que os grupos societais percebem que aquilo que motiva sua atuação nacional é também um problema que ultrapassa as fronteiras nacionais, estabelecem-se contatos pessoais e institucionais com as organizações congêneres de outros países, e este momento permite a criação de identidades coletivas globais a partir das organizações nacionais, as quais passam a agir como subunidades transnacionais identificadas como porta-vozes críticos.

O estabelecimento dessas identidades permite definir, em seguida, uma estratégia coordenada, que fixa métodos de ação e campos de atuação política. Os métodos geralmente aparecem sob duas formas: a sensibilização da opinião pública, para que essa exerça sua pressão sobre os responsáveis pela decisão e execução de projetos e políticas, e a ação direta, que consiste muitas vezes na execução de ações nos próprios lugares onde se desenvolvem os projetos considerados não-procedentes. Com isso, procura-se reforçar a etapa prévia de mobilização da opinião pública. O método de atuação direta pode ser considerado um legado dos grupos ecológicos, que o vêm utilizando sistematicamente desde inícios de 1970. Vale lembrar, a título de ilustração, o incidente de Murora (jurisdição da França) em 1985, que envolveu o governo francês ao afundar a embarcação "Rainbow Warrior", da ONG Greenpeace, trazendo sérias consequiências para o gabinete francês, além do fato de que o embaixador francês na Nova Zelândia chegou a ser advertido diplomaticamente com "pedido de retirada", já que o barco localizava-se nas águas do porto de Auckland (jurisdição da Nova Zelândia) (cf. TREVISÁN COLACRAI, 1988). (Em época recente, a ONG Greenpeace fez uso dos mesmos métodos na França para tentar deter a ação do governo francês de Chirac de levar a cabo testes 
nucleares na mesma região de Murora.) Finalmente, nas duas formas de atuação já relacionadas sensibilização da opinião pública e ação direta é fundamental a sincronia com a mídia nacional e internacional. Poder-se-ia falar que rigorosamente nenhum planejamento é feito sem levar em conta essa condição.

Os dois métodos de atuação descritos acima em geral se fazem acompanhar por uma estratégia de pressão, a qual servirá para influenciar decisões e também determinar o rumo das políticas questionadas, e isso particularmente através de alianças com forças institucionais favoráveis. Dessa forma, um aspecto importante na atuação das ONGs são as parcerias formais e informais que estabelecem na interação com os planos governamental e intergovernamental. Essas parcerias expressam uma grande flexibilidade, o que revela muitas vezes uma face pragmática e instrumental, e inconstância de princípios, não significando, no entanto, que entre as ONGs não existem posições doutrinárias em confronto, como mostra Viola (1987) para o caso das organizações ecológicas. Assim, nas duas últimas décadas, as ONGs vêm servindo aos países desenvolvidos na canalização de recursos para implementar projetos sociais e/ou ambientais em comunidades locais dos países mais pobres ou em desenvolvimento. Em 1975, os países do Primeiro Mundo repassaram cem milhões de dólares para as ONGs do Terceiro Mundo (o que representou 0,7\% da Assistência Oficial ao Desenvolvimento); em 1985, a quantia subiu para um bilhão e cem milhões de dólares. Esse aumento nas quantias repassadas às ONGs revela que se deposita mais confiança na experiência e eficácia desses atores do que nas burocracias oficiais, no que tange à canalização e alocação dos recursos para projetos locais de desenvolvimento (cf. CERNEA, 1989, p. 117-18).

Essas alianças, como forma de estratégia, mostram que as ONGs nem sempre conseguem suas metas em conflito com seus interlocutores. Nisso ajuda o fato de que em geral trata-se de conflitos que utilizam os canais institucionais para sua resolução. Na Conferência do Cairo sobre População e Desenvolvimento, de 1994, deu-se um caso exemplar. Há alguns anos atrás, o Ministério de Relações Exteriores do Brasil, o Itamaraty, não disfarçava seu incômodo com as posições das ONGs das mulheres quando se tratava do assunto aborto, cuja legalização é defen- dida por essas organizações. Naquela conferência, que o Vaticano estava decidido a boicotar para impedir que fosse aprovado o texto que o legalizaria, o Itamaraty teve de procurar o apoio justamente das ONGs das mulheres para sustentar a tese de que, no mínimo, o aborto era uma questão de saúde pública. Esse apoio foi concedido pela diretora executiva do Fundo de População da ONU, Nabis Sadik, nos seguintes termos: "Foi nas ONGs que o governo buscou o apoio que precisava para assumir a posição serena e corajosa que mostrou na conferência" ( $O$ Estado de $S$. Paulo, 14 de setembro de 1994, A-10). Esse caso mostra outra faceta do processo transnacional: a influência que o Estado exerce sobre as ONGs, a qual se explica por diferentes razões, entre elas a possibilidade de aproveitar a experiência das ONGs, a imposição de um ponto de vista de interesse nacional através do controle do representante estatal na ONG e a veiculação de contatos entre os níveis governamentais e não-governamentais.

Em contrapartida, as ONGs têm ganho um status consultivo, tendo o direito de expor seus pontos de vista, de acordo com o tema em pauta. Isso significa institucionalizar a influência das ONGs como prática de lobby. Com efeito, seus representantes nesses organismos são lobistas registrados, estabelecendo com os Estados, dessa forma, relações semelhantes às dos grupos de interesse.

Descrita a inserção quantitativa, qualitativa e estratégica das ONGs nos processos transnacionais e as formas de interdependência com os planos estatais e supranacionais, torna-se necessário determinar em que os fenômenos transnacionais, como os desequilíbrios ecológicos globais, induzem a uma reinterpretação do papel dos atores internacionais. Esse é um problema relevante que se relaciona com a natureza descentralizada dos processos transnacionais.

\section{A DESCENTRALIZAÇÃO DOS PROCES- SOS TRANSNACIONAIS}

Os processos transnacionais - explosão populacional, desequilíbrios ecológicos e migrações internacionais - nos quais se articulam as ONGs, escapam do controle e manipulação política e técnica exclusivos dos centros estatais ou supranacionais, conferindo-lhes um caráter descentralizado. Tome-se como exemplo os desequilíbrios ecológicos globais, quando com- 
parados com o processo termonuclear típico do segundo pós-guerra ${ }^{3}$. Um primeiro contraste é que a forma como os fatores econômicostecnológicos afetam as relações entre Estados supõe uma ampla concorrência pela primazia e controle dos armamentos nucleares. As questões ambientais, diferentemente, não supõem a concorrência de um outro Estado, mas a ameaça de um fator externo, comum a todos e para todos os Estados. Um segundo contraste é que a globalidade das questões termonucleares supõe que o arranjo dos atores hegemônicos é condição suficiente para o funcionamento das regras do jogo (o que vem a ser uma reafirmação do princípio realista de que as relações internacionais articulam-se oligopolisticamente). A globalidade da questão ambiental implica, por sua vez, que os arranjos nos centros hegemônicos podem ser insuficientes ou inócuos sem a colaboração de potências intermediárias e de alguns atores não-estatais, descartando a possibilidade de condomínio dual de superpotências que prevaleceu no período da Guerra Fria. (Para ilustrar, os acordos sobre a camada de ozônio dificilmente seriam atingidos sem a colaboração e participação das transnacionais dos aerossóis, a exemplo da Dupont, uma das principais empresas no mercado desses produtos).

Esse conjunto de características do fenômeno ambiental, que sintetizam de forma geral a natureza dos novos riscos, levam a algumas inferências. De um lado, não se coloca em questão a idéia de que o Estado nacional continua estabelecendo o atributo da soberania, como entidade que define normas, regulamentos e políticas num território, e com isso determinando algumas das pautas para a ação dos atores transnacionais. De outro, porém, a natureza descentralizada dos novos fenômenos faz com que seu controle, às vezes, independa da ação voluntariosa do Estado nacional. De pouco serve o controle do Estado sobre as emissões de bióxido de carbono se não se levar em conta que as mesmas são produzidas pelos sistemas naturais da terra; da mesma forma, pouco se consegue quan-

\footnotetext{
3 O aspecto nuclear-militar é um caso excepcional onde o Estado nacional, como ator individual, é também um ator transnacional.
}

do a Europa e os Estados Unidos aprovam leis de migrações se não se pensa em medidas para controlar o impressionante crescimento de mais de três por cento ao ano da população africana ou para encarar os problemas de desenvolvimento no México. Dadas essas circunstâncias, a influência dos atores transnacionais acaba se definindo pela própria natureza e dinâmica descentralizada, isto é, não exclusivamente estatal dos processos transnacionais.

Como resultado, a inserção dos atores nãoestatais em processos transnacionais descentralizados, isto é, não estratégico-militares, não pode ser compreendida sem que se note que a chamada "autonomia do Estado" foi atingida. Em outros termos: foi afetada a capacidade do Estado de agir e fixar objetivos políticos (entre outros, sua função soberana de discricionariedade para regulamentar o acesso territorial dos atores transnacionais vê-se relativizada pelas restrições impostas pelos processos transnacionais). Como se tornou quase inviável pensar em soluções unilaterais estatais para o problema dos desequilíbrios ecológicos globais, observa-se a procura de formas alternativas de enfrentar o problema, a exemplo do Brasil, onde se está consolidando, a partir de iniciativas dos atores não-estatais, a formação do que tem sido denominado de "terceiro setor": "Um estudo sobre a realidade social na Amazônia, concluído em 1996, revela que sessenta e sete por cento das iniciativas de combate à exclusão são realizadas por organizações do terceiro setor e apenas trinta e três por cento, originárias da administração pública. A maioria das organizações do terceiro setor é formada por produtores rurais, lideranças religiosas, cooperativas e sindicatos de trabalhadores [...]" (MARCOVICHT, 1997, p. 2).

\section{CONCLUSÃO}

A consolidação desses fatos, no nível societal, nos remete a hipóteses - fundamentadas em autores como Capra e Kennedy — de que o Estado tornou-se territorialmente muito pequeno para exercer certas funções, e grande demais para outras (cf. CAPRA, 1988; KENNEDY, 1993). Concluindo, a inserção dos atores societais nos processos transnacionais revela formas de influência quantitativa e qualitativa, dirigidas aos três planos da sociedade internacional aroniana. Essa inserção exprime também estratégias de criação de consenso que incluem mobilização da opinião 
pública e ação direta combinadas, em certos casos, com parcerias pragmáticas com setores go- vernamentais e intergovernamentais.

Recebido para publicação em maio de 1998.

Rafael A. Duarte Villa (rafaduvi@ coruja.humanas.ufpr.br) é Doutor em Ciência Política pela Universidade de São Paulo (USP) e Professor do Departamento de Ciências Sociais da Universidade Federal do Paraná (UFPR).

\section{REFERÊNCIAS BIBLIOGRÁFICAS}

ALVES, L. J. A. 1994. Direitos humanos : o significado político da conferência de Viena. Lua Nova, São Paulo, n. 32.

ALVES, L. J. A. 1995. Conferência do Cairo sobre população e desenvolvimento e suas implicações para as relações internacionais. Working Paper, NAIPE/São Paulo, n. 2, abr.

ARON, R. 1986. Paz e guerra entre as nações. Brasília : Ed. da UnB.

ARON, R. 1997. Os últimos anos do século. Rio de Janeiro : Guanabara.

CAPRA, F. 1988. O ponto de mutação : a ciência, a sociedade e a cultura emergente. São Paulo : Cultrix.

CERNEA, M. 1989. Nongovernmental Organizations and Local Development. Regional Development Dialogue, Washington, n. 10, summer.

DAHL, R. 1966. A moderna análise política. Rio de Janeiro : Lidador Societas.

DUPAS, G. 1993. O emprego em crise: o papel do sindicato deverá ser repensado. $O$ Estado de S. Paulo. São Paulo, 7 de julho.

GILPIN, R. 1989. War and Change in World Politics. Cambridge : Cambridge University Press.

GUIMARÃES, R. 1992. El discreto encanto de la cumbre de la tierra. Evaluación impresionista de Rio-92. Nueva Sociedad, Caracas, n. 22.

GUIMARÃES, R. 1995. O desafio político do desenvolvimento sustentado. Lua Nova, São Paulo, n. 35.

HERTZ, M. 1988. A dimensão cultural das relações internacionais. Contexto Internacional, Rio de Janeiro, vol. IV, n. 8, jul. /dez.

HOFFMAN, S. 1970. International Organizations and the International System. International Organization, San Diego, Ca., vol. XXIV, n. 3.

JACOBSON, H. K. 1989. The Nature of International Organizations. In: RUSSET, B. et alii (eds.). Choices in World Politics. New York : W. H. Freeman and Company.

KAISER, K. 1971. Transnational Politics: Toward a Theory of the Intionational Politics. International Organization, San Diego, Ca., vol. XXV, n. 3, autumn.

KENNEDY, P. 1993. Preparando para o século XXI. São Paulo : Campus.

LEIS, H. 1996. Globalización y democracia en los 90. Hacia un espacio público trasnacional. Nueva Sociedad, Caracas, n. 142, marzo-abril.

LIVERNASH, R. 1992. The Growing Influence of ONGs in the Developing Countries. Environment, London, n. 34, june.

MARCOVITCH, J. 1997. Agenda 21, Estado e ONGs. Jornal da USP, São Paulo, 17 de março.

MELLO VIANNA, F. 1995. Conferência internacional sobre população e desenvolvimento: agenda, tensões e atores no caminho para o Cairo. Contexto Internacional, Rio de Janeiro, vol. 17, n. 1, jan./jun.

MENDERSHAUSEN, H. 1969. Transnational Society versus State Sovereignity. Kiklos, Bonn, vol. XXI, n. 2.

MORGENTHAU, H. 1986. Política entre las naciones. Buenos Aires : Grupo Editor Latinoamericano.

RADAKRISHNA, R. 1991. Guia del Tercer Mundo 91/92. Montevideo : Instituto del Tercer Mundo.

ROSENAU, J. N. 1992. Citizens in a Changing 
Global Order. In: ROSENAU, J. N. e CZEMPIEL, E. O. (eds.). Governance without Government : Order and Change in World Politics. Cambridge : Cambridge University Press.

SHIVA, V. 1991. North-South Conflicts in Global Ecology. Third World Network Features, n. 11 , dec.

SKJELSBAEK, K. 1983. The Growh of International Nongovernmental Organization in the Twentieh Century. In: JOSEPH Jr., N. e KEOHANE, R. (eds.). Trasnantional Relations and World Politics. Cambrige : Harvard University Press.

TOMASSINI, L. 1984. El proceso de trasnacionalización y las relaciones externas de América Latina. . (comp.). Trasnacionalización y desarrollo nacional en América Latina. Buenos Aires : Grupo Editor Latinoamericano.

TREVISÁN COLACRAI, M. 1988. La cuestión del medio ambiente : posiciones extremas desde fuera del sistema antártico (el Grupo Ecológi- co Greenpeace). In: MONETA, C. (ed.). La Antártida no sistema internacional del futuro. Buenos Aires : Grupo Editor Latinoamericano/Centro Latinoamericano de Estudios Estratégicos.

VALENTE, V. V. 1996. Disputando el espacio global. El movimiento de mujeres y la IV conferencia mundial de Beijing. Nueva Sociedad, Caracas, n. 141, enero-febrero.

VIOLA, E. 1987. O movimento ecológico no Brasil (1974-1986). Do ambientalismo à ecopolítica. Revista Brasileira de Ciências Sociais, São Paulo, vol. I, n. 3, fev.

1992. El ambientalismo brasileño. De la denuncia y concientización a la institucionalización y el desarrollo sustentable. Nueva Sociedad, Caracas, n. 122, noviembrediciembre.

WAPNER, P. 1995. Politics Beyond the State: Environmental Activism and World Civic Politics. World Politics, Washington, vol. 47, n. 3.

WEBER, M. 1944. Economia y sociedad. México : Fondo de Cultura Económica.

\section{OUTRAS FONTES}

Nações Unidas. 1994. doc. A/CONF.171/L.1. New York.

O Estado de S. Paulo, 1994; 1996.
Jornal de Brasil, 1997.

Jornal da USP. 
FORMS OF NGOs INFLUENCE IN CONTEMPORARY INTERNATIONAL POLITICS

Rafael A. Duarte Villa (Universidade Federal do Paraná)

This article analyses the growing importance that transnational, non-state actors are aquiring for international relations theory. More specifically, the author explores three facets of this phenomenon: firstly, the proposition of the category of influence as a political means of transnational NGOs performance; secondly, the insertion of these NGOs in global social processes - such as ecological instabilities, human rights, consumption; and finally, the methods of building consensus around social problems of planetary order. The author concludes that NGOs performance affects interstate, supranational and transnational orders.

KEY WORDS: transnacional actor; NGOs; influence; inter-State actor; supranational actor; consensus; decentralization. 
Rafael A. Duarte Villa (Universidade Federal do Paraná)

Cet article analyse l'importance croissante des acteurs non-étatiques transnationaux dans la théorie des relations internationales. L'auteur traite plus particulièrement trois aspects: d'abord la proposition de la catégorie de influence comme moyen d'action politique de l'ONGs transnationale; puis l'implication de cette même ONGs dans le processus sociaux et globaux comme tels que le déséquilibre écologique, le droit de l’homme, la consommation; et enfin les méthodes de création d'un consensus au sujet des problèmes sociaux d'ordre planétaire. L'auteur conclu que l'action des ONGs atteint des niveaux internationaux, supranationaux et transnationaux.

MOTS-CLES: acteur transnational; ONGs; influence; acteur inter-étatique; acteur supranational; consensus; décentralisation. 